\title{
Enzymatic activity of three wild mushrooms
}

\section{Díaz-Godínez $\mathbf{G}^{2}$, Cervantes-Muñoz $\mathbf{P}^{3}$, Acosta-Urdapilleta $\mathbf{M L}^{1}$, Villegas $\mathbf{E}^{4}$, Gupta VK ${ }^{5}$ and Téllez-Téllez $M^{1}$}

\author{
${ }^{1}$ Centro de Investigaciones Biológicas, Universidad Autónoma del Estado de Morelos, Cuernavaca Morelos, México. \\ maura.tellez@uaem.mx,urdapilletal@yahoo.com \\ ${ }^{2}$ Centro de Investigación en Ciencias Biológicas, Universidad Autónoma de Tlaxcala, Tlaxcala, México. \\ diazgdo@hotmail.com \\ ${ }^{3}$ Doctorado en Ciencias Biológicas, Universidad Autónoma de Tlaxcala.lordep28@hotmail.com \\ ${ }^{4}$ Centro de Investigación en Biotecnología, Universidad Autónoma del Estado de Morelos, Cuernavaca Morelos. \\ elbav@uaem.mx \\ Molecular Glycobiotechnology Group, Discipline of Biochemistry, National University of Ireland Galway, Galway, \\ Ireland.vijaifzd@gmail.com
}

Díaz-Godínez G, Cervantes-Muñoz P, Acosta-Urdapilleta ML, Villegas E, Gupta VK, TéllezTéllez M 2016 - Enzymatic activity of three wild mushrooms. Mycosphere 7(10), 1568-1575, Doi $10.5943 / \mathrm{mycosphere} / \mathrm{si} / 3 \mathrm{~b} / 8$

\begin{abstract}
Wild mushrooms are an important cultural patrimony, used since time immemorial as food and medicines according to traditional ecological knowledge. Chemical and biological characteristics of the wild mushrooms are of interest because they are a natural source of great importance for the production of compounds with potential biotechnological applications. Currently are potential producers of metabolites of biotechnological interest, including enzymes, many of which are of great importance in the food industry. In this study the intracellular and extracellular activity of six hydrolases and laccases produced by three wild mushrooms (Lentinula boryana, Pleurotus djamor var. roseus and Pycnoporus sp.) were determined. All strains were grown on potato-dextrose agar and wheat straw-dextrose agar.
\end{abstract}

Key words - Basidiomycetes - hydrolytic enzymes - laccases - white rot fungi

\section{Introduction}

Fungi are integral part of different ecosystems, in the forests are involved in processes such as nutrient cycling and decomposition of organic matter (Herrera \& Ulloa 1998). The white-rot fungi are organisms that have the ability to degrade all components of plants, including lignin, cellulose and hemicellulose (Martínez et al. 2005). Wild mushrooms are considered of the most important non-wood forest products, and are consumed about 3,000 species worldwide. It was estimated that the gain for the collection of edible wild mushrooms was \$2 billion in 2004 (Boa 2004). In Mexico, many species of fungi have been reported as edible and some of them are consumed since prehispanic times, it has been estimated that there are over 300 species of edible wild mushrooms. These mushrooms have ecological, cultural and economic importance for rural communities. However, in Mexico this resource has not been used at its full potential, and economic benefits are limited by lack of organization, processing, regulation and scientific and technological knowledge (Garibay-Orijel et al. 2009). Fungi are an important source of enzymes 
and bioactive compounds in addition to some have great importance as nutraceuticals, have great utility in various industries such as food, pharmaceutical, environmental, among others (Boa 2004). Over 500 products are made using commercial enzymes, the industrial market of these biomolecules in 2009 reached $\$ 5100$ billion, divided into the following areas of application: food $45 \%$ (of which starch processing represents $11 \%$ ), detergents $34 \%$, textiles $11 \%$, leather 3\%, pulp and paper $1.2 \%$ (Sanchez \& Demain 2011). Within industrial enzymes are some hydrolases, such as xylanases, cellulases, pectinases, proteases, amylases, but also include some phenoloxidases and peroxidases.

The wild strain, Lentinula boryana (Berk \& Mont) Pegler (common in the southeastern United States to South America) has been under evaluation for commercial production (Mata \& Guzmán 1993, Mata et al. 2001). Test of interbreeding between Lentinula species, defined the relationship of Lentinula edodes and Lentinula boryana, which are different species but ecologically equivalent (Guzmán et al. 1997). The fungi of genus Pleurotus are called oyster, abalone, or tree mushrooms, is a cosmopolitan group; the pileus may be attached laterally (no stipe). If a stipe is usually eccentric and hymenium is decurrent. These fungi are some of the most commonly cultivated edible mushrooms in the world with a high nutritional value, therapeutic properties, and several environmental and biotechnological applications (Cohen et al. 2002). Several species of Pleurotus have been misidentified, despite its economic importance (Guzmán 2000). Fungi of the genus Pycnoporus has annual fruiting, with smooth pileus, sessile and coriaceous. Shaped of fan ledge, sometimes marked tenuously of concentric zones, in mature specimens this surface is whitish or silvery (Nobles \& Frew 1962, Guzmán 2003). The underside has isodiametric pores ranging in size from small to medium, is a cosmopolitan genus (Ryvarden 1991). In this work, the activities of some hydrolases and laccases of Lentinula boryana, Pleurotus djamor var. roseus and Pycnoporus sp. (native strains of the state of Morelos, Mexico) were quantified.

\section{Material \& Methods}

\section{Organisms}

The stains of Lentinula boryana (HEMIM-44), Pleurotus djamor var. roseus (HEMIM-104) and Pycnoporus sp. (HEMIM-79) were used.

\section{Media and growth condition}

Inoculum from each strain was a plug of mycelium $(4 \mathrm{~mm}$ diam.) taken from the periphery of colonies grown on potato-dextrose agar (PDA). Inoculum was placed (mycelium facing-down) on the center of the Petri dish $(9 \mathrm{~cm}$ diam.) containing either PDA or wheat straw-dextrose agar (SDA). All cultures were incubated at $25{ }^{\circ} \mathrm{C}$ during 7 days, when mycelium invaded almost full the Petri dish.

\section{Extracellular and intracellular extracts}

The extracellular enzymatic extract (EE) was obtained from the agar with deionized water after removing the mycelium from the surface of each colony for every strain. The intracellular EE was obtained from mycelium scraped from the surface of each colony for every strain. Fresh mycelium was ground by using a tissue grinder, in which $1 \mathrm{~mL}$ distilled water was added for each $0.1 \mathrm{mg}$ sample. All the EE were centrifuged at $20000 \mathrm{X} \mathrm{g}$ for $10 \mathrm{~min}$ at $2^{\circ} \mathrm{C}$ (Téllez-Téllez et al. 2005).

\section{Assays of enzyme activities}

Proteases -The reaction mixture contained $450 \mu \mathrm{L}$ of the substrate (casein $1 \%$ in phosphate buffer $0.1 \mathrm{M}$ at $\mathrm{pH} 6.5$ ) and $50 \mu \mathrm{L}$ of $\mathrm{EE}$, incubated $15 \mathrm{~min}$ at $35^{\circ} \mathrm{C}$, was subsequently added 700 $\mu \mathrm{L}$ of $5 \%$ trichloroacetic acid and centrifuged at 14,000 rpm for $10 \mathrm{~min}$. Was measured the absorbance of the supernatant at $280 \mathrm{~nm}$ (Kunitz 1947). Cellulases - The reaction mixture 
contained $950 \mu \mathrm{L}$ of substrate (carboxymethylcellulose $1 \%$ in acetate buffer $0.1 \mathrm{M}$ at $\mathrm{pH} 4.8$ ) and $50 \mu \mathrm{L}$ of EE. The reaction mixture was incubated at $50{ }^{\circ} \mathrm{C}$ for $15 \mathrm{~min}$. Xylanases - The reaction mixture contained $950 \mu \mathrm{L}$ of the substrate (xylan $0.5 \%$ in acetate buffer $0.1 \mathrm{M}$ at pH 5.3) and $50 \mu \mathrm{L}$ of EE. The reaction was incubated at $50{ }^{\circ} \mathrm{C}$ for $15 \mathrm{~min}$. Pectinases - The reaction mixture contained $950 \mu \mathrm{L}$ of substrate (polygalacturonic acid $1 \%$ in acetate buffer $0.1 \mathrm{M}$ at $\mathrm{pH} 5.0$ ) and $50 \mu \mathrm{L}$ of EE. The reaction was incubated at $45^{\circ} \mathrm{C}$ for $15 \mathrm{~min}$. Amylases - The reaction mixture contained $950 \mu \mathrm{L}$ of substrate (starch at $1 \%$ in acetate buffer $0.1 \mathrm{M}$ at $\mathrm{pH} 5.5$ ) and $50 \mu \mathrm{L}$ of EE. The reaction was incubated at $50{ }^{\circ} \mathrm{C}$ for $20 \mathrm{~min}$. Invertases - The reaction mixture contained $950 \mu \mathrm{L}$ of substrate (sucrose $0.1 \mathrm{M}$ in acetate buffer $0.1 \mathrm{M}$ at $\mathrm{pH} 5.5$ ) and $50 \mu \mathrm{L}$ of EE. The reaction was incubated at 30 ${ }^{\circ} \mathrm{C}$ for $30 \mathrm{~min}$. The activities of cellulases, xylanases, pectinases, amylases and invertases were determined by measuring the release of reducing sugars from respective substrates using acid 3-5, dinitrosalicylic (DNS method; Miller 1959). After the incubation period, $2 \mathrm{~mL}$ of DNS were added to each tube and were placed in boiling water for 5 minutes, allowed to cool and then was read the absorbance at $575 \mathrm{~nm}$. A calibration curve for each activity using known concentrations of respective monosaccharide was made. Laccases - The reaction mixture contained $950 \mu \mathrm{L}$ of substrate (2,6-dimethoxyphenol at $2 \mathrm{mM}$ in acetate buffer $0.1 \mathrm{M} \mathrm{pH} \mathrm{4.5)} \mathrm{and} 50 \mu \mathrm{L}$ of EE. The increase of absorbance was followed in a PELTIER cell at $40{ }^{\circ} \mathrm{C}$ for one min. The hydrolytic activities were reported in international units per g dry biomass (U/gX). The unit of either proteases or laccases, was considered as the amount of enzyme that increased one absorbance unit in the reaction mixture per min and also was reported in $\mathrm{U} / \mathrm{gX}$ (Téllez-Téllez et al. 2008). All activity values were reported as mean \pm standard deviation.

\section{Results}

The three strains showed very different characteristics when grown on PDA than in SDA (Fig. 1). Lentinula boryana and Pleurotus djamor var. roseus grew on PDA very slow compared when grown on SDA; Mycelium of Pycnoporus sp. grown on PDA was thinner compared with mycelium developed on SDA.

Intracellular and extracellular enzyme activities were observed in all cases evaluated in this study (Fig. 2). In general, the values of extracellular activity were higher than the intracellular activities; the SDA medium showed the enzyme activity values higher compared to those reported in the PDA medium. The intracellular activity values of pectinases, amylases, invertases and proteases were similar, regardless of the culture medium and strain studied (approximately 10-30 $\mathrm{U} / \mathrm{gX}$ ), suggesting that are enzymes that do not alter their intracellular level, it is possible that were identified only enzymes that were in transit to be excreted. Cellulases and xylanases showed different intracellular activity values, depending on the strain and culture medium, Lentinula boryana showed the highest values (approximately $80 \mathrm{U} / \mathrm{gX}$ ) followed by Pleurotus djamor var. roseus. Intracellular laccase activity was minimal in PDA medium (Fig. 2a), while in the SDA medium (Fig. 2b), very high values in the strains of Pycnoporus sp. and Pleurotus djamor var. roseus were observed (approximately 110-118 U/gX) with regarding Lentinula boryana strain (about $5 \mathrm{U} / \mathrm{gX}$ ).

Extracellular activity had higher variations (Fig. 3), and clearly showing that the SDA medium reported the highest enzymatic activity values in the three strains (except for amylases of Pleurotus djamor var. roseus). In PDA medium (Fig. 3a), the activity values of cellulases, xylanases, proteases and invertases were minimal for the strains of Pycnoporus sp., Lentinula boryana and Pleurotus djamor var. roseus. This last strain showed very high values of the activity of amylase and pectinase compared to the other two strains (approx. 700 to $2000 \mathrm{U} / \mathrm{gX}$, respectively), it is possible that in Pleurotus djamor var. roseus, an inductive effect was observed for amylases, as the culture medium containing glucose and potato extract which is rich in starch. Lentinula boryana strain showed the highest values of laccase activity $(650 \mathrm{U} / \mathrm{gX})$, being approximately 10 times higher than that observed in the other two strains. In the SDA medium (Fig. 3b), Lentinula boryana showed the highest enzyme activity values with respect to the other two strains, pectinases activity value $(1657 \mathrm{U} / \mathrm{gXs})$ was four and eight times higher than those reported 


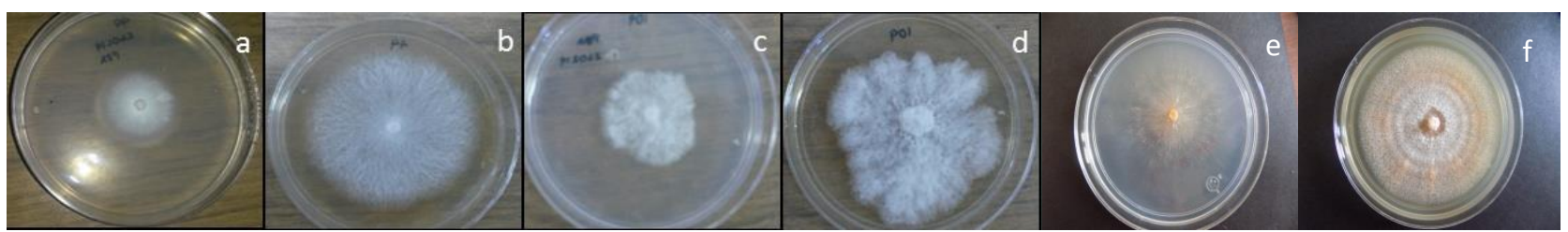

Fig. 1 - Mycelia growth of the three strains Lentinula boryana grown on PDA (a) and SDA (b), Pleurotus djamor var. roseus grown on PDA (c) and SDA (d) and Pycnoporus sp. grown on PDA (e) and SDA (f).
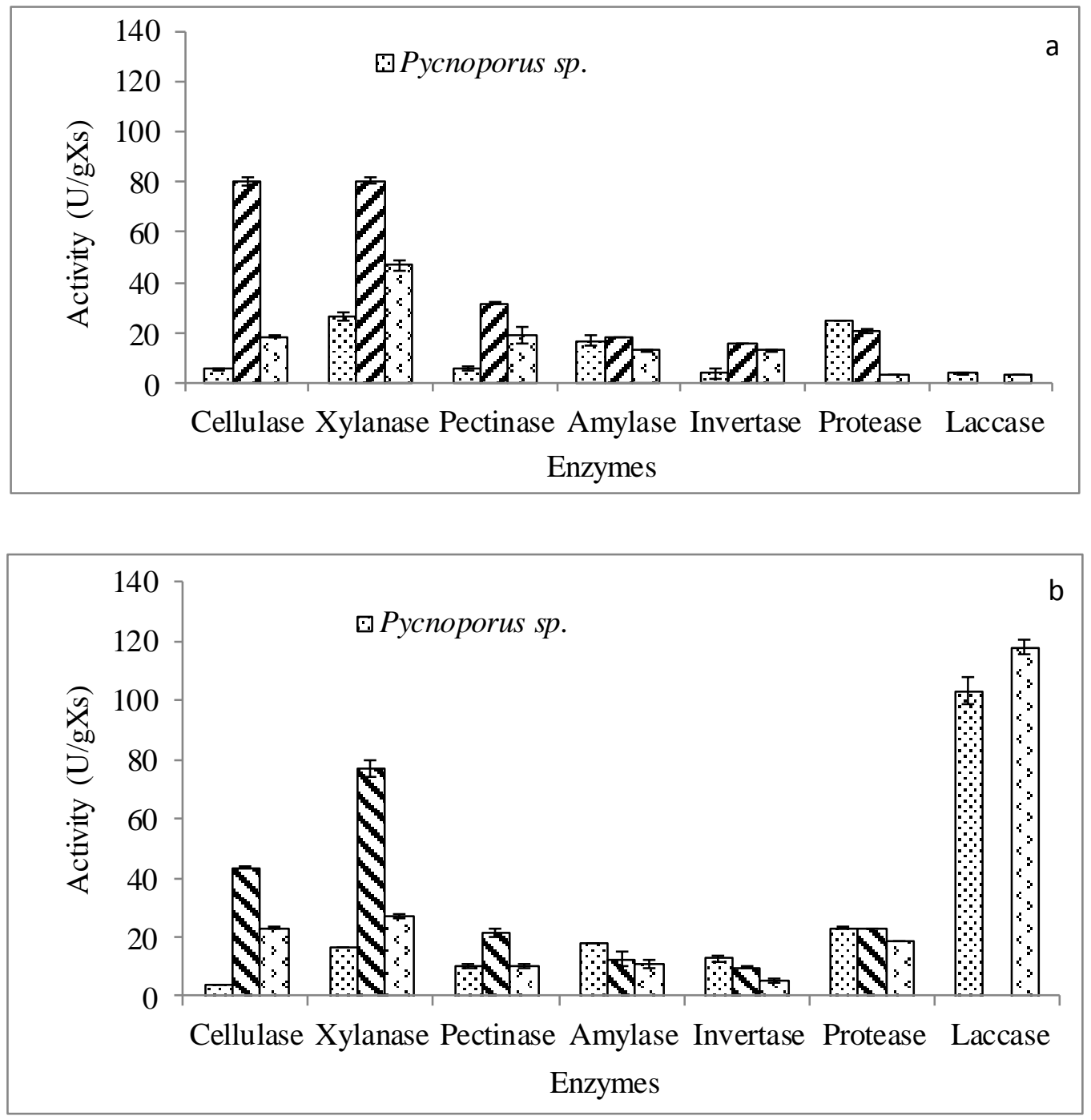

Fig. 2 - Hydrolytic and laccase intracellular activities from strains of wild mushrooms grown on PDA (a) and SDA (b).

by Pycnoporus sp. and Pleurotus djamor var. roseus, respectively; amylases activity value (1554 $\mathrm{U} / \mathrm{gXs}$ ) was $40 \%$ higher and the laccase (1630 U/gXs) was 14 y $30 \%$ higher (Pycnoporus sp. and Pleurotus djamor var. roseus, respectively). These results showed that the wild mushrooms are a potential group of enzyme producers, and the activity values might be increased modifying the culture conditions of the mushrooms. 


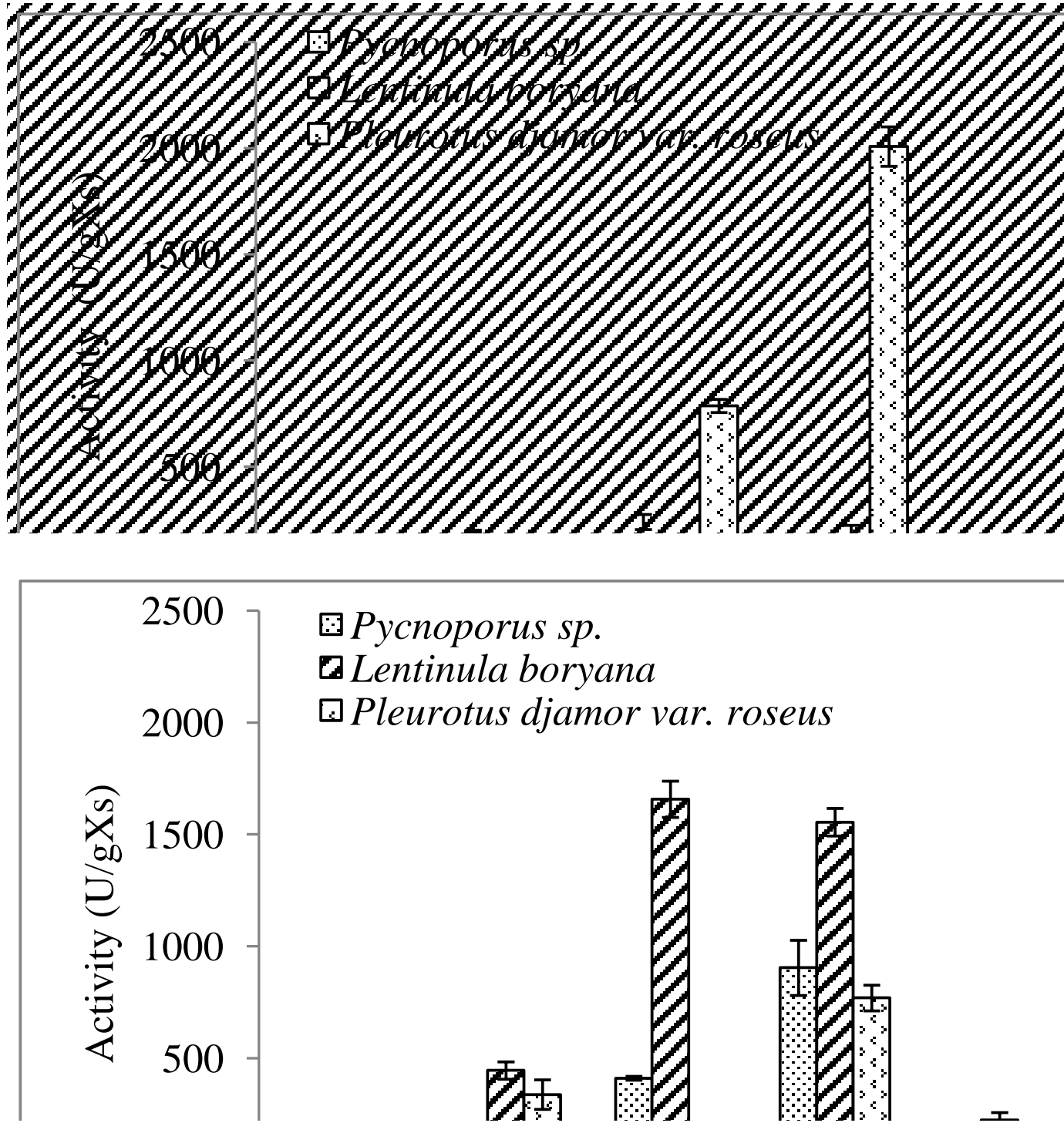

Fig. 3 - Hydrolytic and laccase extracellular activities from strains of wild mushrooms grown on PDA (a) and SDA (b).

\section{Discussion}

In other studies, were reported the enzymatic activities from different fungi, such as, the studies of Álvarez-Cervantes et al. (2013), which reported approximately 12000 U/L of xylanases by Sporisorium reilianum developed in submerged fermentation $(\mathrm{SmF})$ in the presence of birch xylan. Amylases, cellulases and invertases activities reached values around 500, 1500 and 250 U/L, respectively. In a recent study reported that Stenocarpella maydis, the cellulase activity produced almost 8000 and $9500 \mathrm{U} / \mathrm{L}$ in SmF and solid-state fermentation (SSF) respectively (HernándezDomínguez et al. 2014). Téllez-Téllez et al. (2008) proposed a growth medium with the presence of copper as inductor, glucose as carbon source and yeast extract as nitrogen source that allowed the increase the laccase activity of Pleurotus ostreatus, reporting to $14000 \mathrm{U} / \mathrm{L}$ in SmF and 5000 U/L in SSF using polyurethane foam as inert support. In a recent study, was reported about 38,000 U/L of laccases by Pleurotus ostreatus grown in $\mathrm{SmF}$, where the $\mathrm{pH}$ was an important factor for the different activity levels, also reported that $\mathrm{pH}$ of production is not the same for the enzyme activity (Díaz et al. 2013). This information could be used to improve the activity by the strains studies in this work. On the other hand, the composition of culture media is important, since in this study the SDA medium showed better growth of the three strains than in PDA medium, possibly the SDA medium is complex having major nutrients in comparison to PDA medium. 
Kalmiş et al. (2008) worked with commercial and wild strains. Pleurotus ostreatus and Pleurotus citrinopileatus (commercial strains) showed at $27^{\circ} \mathrm{C}$ and 14 days of culture, the highest (62.39 U/L) and the lowest (1.68 U/L) laccase extracellular activities, respectively. In the case of wild strains, which showed highest activity was Pleurotus ostreatus-4 (941.66 U/L), followed by Pleurotus eryngii-1 (162.5 U/L), Pleurotus ostreatus-1 (119.41 U/L) and Pleurotus eryngii-2 (109.50 U/L). Periasamy \& Natarajan (2004) reported that Pleurotus djamor var. roseus showed enzymatic activities of cellulases, lignin peroxidases and laccases. Extracellular activity patterns were correlated with the growth and fruiting body formation, and the substrate was important in the amount of enzymes produced. Jonathan \& Adeoyo (2011) reported very good amylase and cellulase activities of some wild fungi. With the incorporation of carboxymethyl-cellulose (a carbon source) into the culture medium, Agaricus blaze $i$ had the highest amylolytic activity $(0.60 \mathrm{U} / \mathrm{mL}$ at $25^{\circ} \mathrm{C}, \mathrm{pH}$ 6.8). This was followed in order by Pleurotus tuber-regium and Agaricus sp. with 0.42 and $0.39 \mathrm{U} / \mathrm{mL}$, respectively.

Khaund \& Joshi (2014) reported the enzymatic patterns of wild edible mushrooms (14 species), the specimens Inocybe sp., Cantharellus cibarius (Fr.), Lactarius deliciosus (L. ex Fr.) S.F.Gray, Lactarius volemus (Fr.) Fr., Laccaria lateritia, Ramaria sp. and Clavulina sp. showed high amylase activity (approximately $30 \mathrm{U} / \mathrm{mL}$ ) and very low cellulase activity (around of 4.41 $\mathrm{U} / \mathrm{mL}$ ), whereas Gomphus floccosus (Schw.) Singer, Albatrellus sp. and Tricholoma saponaceum (Fr.) P. Kumm showed low amylase activity $(<20 \mathrm{U} / \mathrm{mL})$, and the highest protease activity (approximately $50 \mathrm{U} / \mathrm{mL}$ ). Interestingly, the same specimen Inocybe sp. also showed the highest cellulase activity $(20.26 \mathrm{U} / \mathrm{mL})$.

Ten mushroom specimens under investigation showed considerable laccase activity under the assay conditions, with activity values ranging from 13.54 to $99.38 \mathrm{U} / \mathrm{mL}$. The cellulolytic activities of the widely consumed edible mushroom Pleurotus ostreatus from Egypt has been reported by Daba et al. (2011), in which promising endo and exoglucanase activities were shown. Krupodorova et al. (2014) reported six extracellular enzymatic activities obtained in thirty cultures of macromycetes of different ecophysiological (wood decaying, saprotrophic, entomophilous, and leaf-litter decaying). Amylase activity was detected in all investigated mushroom cultures, lipase in 26, laccase in 21 and urease in 20. Protease activity was revealed in 6 species and nitrate reductase activity only in Lepista luscina and Morchella esculenta. As a whole, Lepista luscina with its amount of detected enzymes and their good visualization seemed to be a promising species. Some of investigated mushrooms are reported as species producing extracellular enzymes investigated in this study for the first time: Hohenbuehelia myxotricha, Lepista luscina, Lyophyllum schimeji, Phellinus igniarius, Piptoporus betulinus, and Spongipellis litschaueri (amylase); Lepista luscina, Crinipellus schevczenkovi, Auriporia aurea, Hypsizygus marmoreus, Lyophyllum schimeji, Oxyporus obducens, and Spongipellis litschaueri (laccase).

\section{Conclusion}

The possibility of synthesis of various enzymes is encoded in the genome of the fungus, and can be performed under certain growth conditions. Results of this study, suggest that is important to perform studies of wild edible mushrooms, which are potential producers of enzymes of industrial interest and application in bioremediation processes. Pleurotus djamor var. roseus, Pycnoporus sp. and Lentinula boryana are wild mushroom from state of Morelos, Mexico with important enzyme activity, whose activity values could be improved by optimizing the growth conditions.

\section{Acknowledgements}

Thanks to PRODEP by supporting this research trough de project UAEMOR-PTC-336 and to The National Council of Science and Technology of Mexico (CONACYT) for supporting scientific stay of Gerardo Díaz Godínez (Application 233234). 


\section{References}

Álvarez-Cervantes J, Hernández-Domínguez EM, Arana-Cuenca A, Díaz-Godínez G, MercadoFlores Y. 2013 - Purification and characterization of xylanase SRXL1 from Sporisorium reilianum grown in submerged and solid-state fermentation. Bioresources 8, 5309-5318.

Boa ER. 2004 - Wild edible fungi: a global overview of their use and importance to people. Technical papers, Food \& Agriculture Organization. 17. Publishing Management Service.

Cohen R, Persky L, Hadar Y. 2002 - Biotechnological applications and potential of wood degrading mushrooms of the genus Pleurotus. Applied Microbiology and Biotechnology 58, 582-594.

Daba AS, Youssef GA, Kabeil SS, Hafez EE. 2011 - Production of recombinant cellulase enzyme from Pleurotus ostreatus (Jacq.) P. Kumm. (type NRRL-0366). African Journal of Microbiology 5, 1197-202.

Díaz R, Téllez-Téllez M, Sánchez C, Bibbins-Martínez MD, Díaz-Godínez G, Soriano-Santos J. 2013 - Influence of initial $\mathrm{pH}$ of the growing medium on the activity, production and genes expression profiles of laccase of Pleurotus ostreatus in submerged fermentation. Electronic Journal of Biotechnology 16 (4), DOI: 10.2225/vol16-issue4-fulltext-6.

Garibay-Orijel R, Martínez-Ramos M, Cifuentes J. 2009 - Disponibilidad de esporomas de hongos comestibles en los bosques de pino-encino de Ixtlán de Juárez, Oaxaca. Revista Mexicana de Biodiversidad 80, 521-534.

Guzmán G, Salmones D, Tapia F. 1997 - Lentinula boryana: morphological variation, taxonomic position, distribution and relationships with Lentinula edodes and related species. Reports of the Tottori Mycological Institute (Japan) 35, 1-28.

Guzmán G. 2000 - Genus Pleurotus (Jacq.:Fr) P.Kumm. (Agricomycetidae): diversity, taxonomic problem and cultural and traditional medical uses. International Journal of Medicinal Mushrooms 2, 95-123.

Guzmán G. 2003 - Hongos de El Edén Quintana Roo. (Introducción a la micobiota tropical de México). INECOL y CONABIO, Xalapa.

Hernández-Domínguez EM, Rios-Latorre RA, Álvarez-Cervantes J, Loera-Corral O, RománGutiérrez AD, Díaz-Godínez G, Mercado-Flores Y. 2014 - Xylanases, cellulases, and acid protease produced by Stenocarpella maydis grown in solid-state and submerged fermentation. Bioresources 9, 2341-2358.

Herrera T, Ulloa M. 1998 - El Reino de los Hongos. Universidad Nacional Autónoma de México. Fondo de Cultura Económica. México.

Jonathan SG, Adeoyo OR. 2011 - Evaluation of ten wild Nigerian mushrooms for amylase and cellulase activities. Mycobiology 39(2), 103-108.

Kalmiş E, Yaşa I, Kalyoncu F, Pazarbaşi B, Koçyigit A. 2008 - Ligninolytic enzyme activities in mycelium of some wild and commercial mushrooms. African Journal of Biotechnology 7 , 4314-4320.

Khaund P, Joshi SR. 2014 - Enzymatic profiling of wild edible mushrooms consumed by the ethnic tribes of India. Journal of the Korean Society for Applied Biological Chemistry 57, 263 271.

Krupodorova T, Ivanova T, Barshteyn V. 2014 - Screening of extracellular enzymatic activity of macrofungi. The Journal of Microbiology, Biotechnology and Food Sciences 3, 315-318.

Kunitz M. 1947 - Crystalline soy bean trypsin inhibitor. General properties. The Journal of General Physiology 30, 291-310.

Martínez AT, Speranza M, Ruiz-Dueñas FJ, Ferreira P, Camarero S, Guillén F, Martínez MJ, Gutiérrez A, del Río JC. 2005 - Biodegradation of lignocellulosics: microbiological, chemical and enzymatic aspects of fungal attack to lignin. International Microbiology 8, 195-204. 
Mata G, Delpech P, Savoie JM. 2001 - Selection for strain of Lentinula edodes and Lentinula boryana adapted for efficient mycelial growth on wheat straw. Revista Iberoamericana de Micología 18, 118-122.

Mata G, Guzmán G. 1993 - Cultivation of Lentinus boryana in wood shaving in Mexico. Cryptogamic Botany 4, 47-49.

Miller GL. 1959 - Use of dinitrosalicylic acid reagent for determination of reducing sugar. Analytical chemistry 31, 426-429.

Nobles MK, Frew BP. 1962 - Studies in wood-inhabiting hymenomycetes. V. The genus Pycnoporus Karst. Canadian Journal of Botany 40, 987-1016.

Periasamy K, Natarajan K. 2004 - Role of lignocellulosic enzymes during basisiomata production by Pleurotus djamor var. roseus. Indian Journal of Biotechnology 3, 577-583.

Ryvarden L. 1991 - Genera of polypores, nomenclature and taxonomy. Synopsis Fungorum 5. Fungiflora, Oslo.

Sanchez S, Demain AL. 2011 - Enzymes and bioconversions of industrial, pharmaceutical and biotechnological significance. Organic Process Research \& Development 15, 224-230.

Téllez-Téllez M, Fernández JF, Montiel-González AM, Sánchez C, Díaz-Godínez G. 2008 Growth and laccase production by Pleurotus ostreatus in submerged and solid-state fermentation. Applied Microbiology and Biotechnology 81, 675-679.

Téllez-Téllez M, Sánchez C, Loera O, Díaz-Godínez G. 2005 - Differential patterns of constitutive intracellular laccases of the vegetative phase for Pleurotus species. Biotechnology Letters 27, 1391-1394. 